\title{
Indian time: time, seasonality, and culture in Traditional Ecological Knowledge of climate change
}

\author{
Samantha Chisholm Hatfield ${ }^{1 *}$ (D) Elizabeth Marino ${ }^{2}$, Kyle Powys Whyte ${ }^{3,4}$, Kathie D. Dello ${ }^{1}$ and Philip W. Mote ${ }^{1}$
}

\begin{abstract}
Introduction: Western climate science and Traditional Ecological Knowledge (TEK) represent complementary and overlapping views of the causes and consequences of change. In particular, observations of changes in abundance, distribution, phenology, or behavior of the natural environment (including plants and animals) can have a rich cultural and spiritual interpretation in Indigenous communities that may not be present in western science epistemologies.

Results: Using interviews with Indigenous elders and other Traditional Knowledge holders, we demonstrate that assumptions about the nature, perception, and utilization of time and timing can differ across knowledge systems in regard to climate change.

Conclusions: Our interviewees' focus on relationality predisposes them to notice interactional changes among humans and other species, to be sensitive to smaller scale examples of change, to be more likely to see climate change as part of a broader time scale, and to link changes to a greater suite of socio-political phenomena, including the long arc of colonialism. One implication of this research and the interactions among humans and other species is that policies restricting Native and non-Native access to resources (i.e., hunting and fishing) to certain calendar seasons may need to be revisited in a changing climate.
\end{abstract}

Keywords: Traditional Ecological Knowledge (TEK), Traditional Knowledge (TK), Indigenous Knowledge (IK), Climate change, Phenology, Seasonality, Time

\section{Introduction}

Indigenous peoples around the world have been some of the most vocal in acknowledging that (a) climate change is visibly occurring; and (b) that their communities, and all communities, should mitigate, plan for, and adapt to those changes (Harrington 2006; Maldonado et al. 2017; The Mystic Lake Declaration 2009; Wildcat 2009). This vocality, and the organizing around it (Salick and Byg 2007, Maldonado et al. 2017), has brought new prominence of TEK within climate science ${ }^{1}$ that takes many different forms. Some mainstream scholars acknowledge the unique and complementary value of TEK in providing additional information about changes in the natural world (e.g., phenology) that are not as readily available

\footnotetext{
* Correspondence: shatfield@coas.oregonstate.edu

${ }^{1}$ Oregon Climate Change Research Institute, Oregon State University, 104

CEOAS Admin Building, Corvallis, OR 97331, USA

Full list of author information is available at the end of the article
}

through western science observations (Berkes et al. 2000; Huntington 2000; Drew 2005). This utilitarian view can selectively admit TEK into the western view of climate change or climate change adaptation. Here, TEK often serves as data that are useful for scientific research, for describing climate change impacts, or for adaptation wisdom that may support community-level planning efforts.

Another form is to focus on how climate change uniquely affects Indigenous communities (e.g., Bennett et al. 2014). For example, Field et al. (2014) note that one risk connected with sea-level rise is "Loss of common-pool resources, sense of place, and identity, especially among Indigenous populations in rural coastal zones." In the USA at least, recognition that Indigenous peoples face special challenges connected to climate change has led to some dedicated research and engagement resources directed toward Indigenous communities 
and nations from governments, non-governmental organizations, universities, and the media (Bennett et al. 2014; Wotkyns 2013). A third alternative (that may include one or both models above) is research conducted by Indigenous scholars and scientists themselves (formally or informally), either through university and government research institutions, or as community-driven knowledge production. These latter examples often take the form of practical climate change adaptation planning such as the Climate Adaptation planning with the Institute for Tribal Environmental Professionals at Northern Arizona University (https://www7.nau.edu/itep/main/Home/).

However, while these two primary sets of knowledge (mainstream and Indigenous) can and do inform one another, their epistemological differences are significant and deserve examination. Indigenous peoples often interpret the nature and significance of climate change differently from non-Indigenous scientists (Bennett et al. 2014; Chief et al. 2014; Maldonado et al. 2013; Vinyeta et al. 2015; Willox et al. 2011). These differences may significantly affect the production of science, and the relationships among non-Indigenous scientists, Indigenous scientists, and communities experiencing change (Williams and Hardison 2013).

The literature points to several differences between these two sets of knowledge. First, while western scientists usually describe vulnerability to climate change in economic or ecological terms, or occasionally mention deeper effects (as in the Field et al. quote above, about identity, or Lynn et al. 2013 about tribal first foods), many Indigenous peoples and communities approach the question of how climate change affects them quite differently. They see themselves additionally vulnerable psychologically and existentially, and see climate change as threatening the integrity of their communities' cohesion, or as altering the existential, personal, and intimate (as opposed to metaphorical or consumptive) relationships with the natural world (Maldonado 2012; Maldonado et al. 2013; Marino 2012; Willox 2012; Willox et al. 2011; LaDuke 2017; Whyte et al. 2016).

Second, climate science-when describing changes to the environment-draws sharp distinctions between empirical data (whether observed or modeled) and the sociocultural context of those data. By contrast, Indigenous peoples often understand the nature and significance of their knowledges within political, environmental, cultural, and social systems that differ greatly from those of many scientists (Climate and Traditional Knowledges Workgroup 2015; Whyte 2016b; Williams and Hardison 2013).

Third, related to cause, scientists and other non-Indigenous persons distinguish natural climate variability from anthropogenic (human-caused) climate change through a rigorous statistical process aimed at determining, e.g., how much of the warming in the past half-century was caused by rising greenhouse gases (Stocker et al. 2013). Yet Indigenous peoples, and some scholarly and activist commentators, link climate change with other environmental and social changes that are related to longstanding issues of power, especially colonialism (both historically and today) and exploitative business practices (Cameron 2012; Haalboom and Natcher 2012; Marino 2015; Whyte 2016a; Wildcat 2009).

Missing from this literature is a comparison of the epistemology of time between scientific and Indigenous Knowledge sets. Moreover, because one important aspect of climate change is changes in seasonality (the regular occurrence of natural events), understanding how different knowledge sets relate to time and seasonality is essential for understanding these different ways of knowing, how they are complementary, and how they may differ. The specific objective of this paper is to present Indigenous Knowledge holders' understanding of ecological change, and any shifts that may be climate change driven, as perceived through the lens of TEK in their communities and to identify the assumptions about time and seasonality that are made therein based on western scientific understandings. We argue that traditional ways of knowing are not only valid, they are built on a different intellectual and cultural framework that needs to be understood in its own right. We compare those assumptions with assumptions in the climate science literature on time and timing in the same region. This comparison provides important insights into assumptions (when studying climate change) about the nature of time, what subsequent to those assumptions becomes more likely to be observed, and what counts as information within these epistemological systems, as well as the outcomes and adaptation possibilities that stem from that knowledge. Furthermore, this study demonstrates how Indigenous Knowledge of the environment and/or TEK may detect changes that are imperceptible to western science, in part, because of a unique and holistic relationship with the timing of change.

\section{Knowing about time and the timing of knowing}

Knowledge systems, which derive from institutions that furnish their reliability, represent approaches to gaining a reliable understanding of the world we inhabit so that societies flourish. Scientific peer review is such an institution, as is gaining promotion and rank in organizations. In Indigenous communities, complex knowledge systems are sometimes referred to as Traditional Ecological Knowledge (TEK). For the purposes of this paper, TEK is defined as the application of the specific area of Indigenous Traditional Knowledge and Indigenous Science Knowledge that relates to the environment in a given traditional homeland of Indigenous groups and/or Usual and Accustomed (U\&A) areas. This may include 
but is not limited to botany knowledge, medicinal application (collection and/or administration), hunting, fishing, gathering, processing of material(s), caretaking such as burning, coppicing, thinning, astronomy, phenology, time, ecological markers, species markers, weather and climate knowledge (Hong et al. 2018). TEK is complex, unique, and can include a suite of experts, institutions, referendums on knowledge, and checks and balances for ensuring the successful creation, accumulation, and transfer of knowledge, information, and ethical guidance on how to use that information (Cochran et al. 2013; Barnhardt and Kawagaley 2005). Ceremonies, such as potlatch ceremonies, and training protocols for harvesters, as just two examples, have been discussed in the literature as institutions that support the reliability of Indigenous Knowledge systems (Trosper 2009). Ceremonies and ceremonial areas vary from tribal group, area, and location. Some ceremonial practices are intellectual property and are not released information, while other ceremonial practices are adjusted and moved depending on TK and TEK.

Perceptions of time and temporality are deeply intertwined with knowledge creation, accumulation, and transfer, as well as cultural orientation (Gingrich et al. 2002 ), and can vary greatly from one knowledge community to another. In some contexts, time is presumed to be the linear progression of certain events happening one after another. This presumption is now understood as profoundly ethnocentric and "brazenly cultural in character." (Hodges 2008). As Bates writes "Assumptions about time as a linear flow of constant rate, with neat chronologies linking events in the past, present, and future are convictions that are deeply embedded in Western thought" (Bates 2007), and thus, embedded in Western, non-Indigenous scientific discourses.

Conversely, conceptions of time in Indigenous contexts can vary widely and are often encoded in Indigenous languages or methods of discourse and knowledge exchanges, including storytelling and explanations about the relationships among things in place. Different ontologies also highlight different metaphorical constructions to explain the flow of time. For example, among Aymara speakers of South America, the present-past is visible and perceivable, but the future is behind a person and, therefore, un-seeable and unknowable. Similar constructions of present-past and future are present in Tuvaluan languages and larger Pacific cultural groups, and these constructions can clash with Western scientific discourses on climate change which posit that an adequate understanding of processes and other information permit reasonably accurate quantitative predictions and are thus oriented toward the future (Marino and Lazrus 2016). Indigenous scholars and scholars of Indigenous studies discuss the differences in concepts of time.
Stewart-Harawira (2005) claims that "Within Māori ontological and cosmological paradigms it is impossible to conceive of the present and the future as separate and distinct from the past, for the past is constitutive of the present and, as such, is inherently reconstituted within the future" (Stewart-Harawira 2005). In the Anishinaabemowin (Neshnabémwen) language, the expression aanikoobijigan (yankobjegen) (Whyte 2018, pg. 5) means ancestor and descendent at the same time. This meaning suggests an Anishinaabe perspective on intergenerational time-a perspective embedded in cyclicality in which it makes sense to consider ourselves as living alongside future and past relatives simultaneously as we walk through life. Cyclical time or cyclical temporality, here, refers to various ways of experiencing ourselves in the world as participants within narratives involving our ancestors and descendants.

We know, additionally, that climate change will include changes in temporality, timing, and seasonal shifts. These changes in seasonality have been widely noted. Particularly in the Arctic, researchers and Indigenous residents have noted changing in the timing and intensity of weather patterns such as rain, snow, or cloud cover (Huntington and Fox 2005; McNeeley and Shulski 2011; Robinson and Frei 2000). Some research has indicated that these changes, while relatively small when measured by climate scientists, can indicate important seasonality shifts for people engaged in subsistence practices (McNeeley and Shulski 2011; Weatherhead et al. 2010).

Seasonality does not refer to the commonly accepted four seasons, but rather how annual environmental changes affect harvesting, monitoring, storing, and consuming of sometimes hundreds of plants, animals, and insects. Seasonal perceptions of climate change may be tied to detailed accounts of movements of plant, animal, and insect populations and conditions such as ice cover or water levels that differ from perceptions of climate change rooted only in changes of precipitation or temperature on a four seasons model of annual change. For example, many Indigenous peoples perceive more than four seasons, such as the Anishinaabe 13 moons system or "seasonal round" (Davidson-Hunt and Berkes 2003; Benton-Banai 2008).

Indigenous perspectives on time, seasonality, and the impacts of climate change have not previously been compared with perspectives from climate science in the western USA. Natural scientists have demonstrated significant changes in climate (e.g., Abatzoglou et al. 2014) and some consequences of those changes (e.g., Dalton et al. 2013). Native American communities are also recognizing change (Charnley et al. 2007; Alexander et al. 2011). Our original goal in this research was to investigate the observations of five tribes in the western USA, 
utilizing a TEK perspective, to discover whether they perceived impacts of climate change impacts, and whether any adaptive strategies were being implemented. Research can produce surprises, and the same was true with this project. We initially expected to focus on visible expressions of culture, including songs, stories, dances, and ceremonies, but the dominant emphasis in interviews led us to emergent results concerning deeper notions of how one frames change, responses to change, and the interactions among species, ecosystems, and culture. These observations are linked to notions and perceptions of time and seasonality that appeared quite different, in certain ways, from their climate science counterparts.

\section{Methods}

The overall research objective of this project at its inception was to identify the behaviors and patterns of Native American culturally relevant natural resources through a TEK lens and note responses, if any, to climate change. We did this by the following: (1) interviewing tribal elders and cultural experts from five carefully chosen tribes (Fig. 1): the Confederated Salish Kootenai Tribes, the Confederated Tribes of Siletz Indians, the Paiute Shivwits Band, the Duckwater Shoshone, and the Quinault Indian Nation, and classifying their responses about cultural impacts; (2) comparing responses and adaptation measures; and (3) comparing those findings with climate science findings in the same region. The five tribes selected were all from the west and included the Pacific Northwest and Great Basin regions.

The categories of questions included (a) plants and animals responding to changing climate conditions; and (b) elements of tribal tradition and culture that depend heavily on those plants and animals. However, our interviews were intended to establish, primarily, the last causal step: (c) whether the fluctuations in the abundance and distribution of plants and animals and other environmental factors have resulted in modifications or adaptations of tribal cultural traditions or other aspects of culture. Interviewees were not asked to speculate on the influence of global or regional climate change, and it was not the intention of this research to establish, through new analysis, whether any of these changes mentioned by interviewees are a consequence of climate change.

\section{Selection of tribes}

We chose the aforementioned five tribes with high engagement and promotion of traditional cultural activity on their websites, similar enrollment numbers, and breadth of geographic distribution ranging from coastal to mountain to desert. None of the tribes selected are directly connected to each other, but are autonomous, federally recognized sovereign tribes located within the western USA.

\section{Recruitment and data collection}

The lead author interviewed 24 members of the five tribes. The participants were chosen based on their

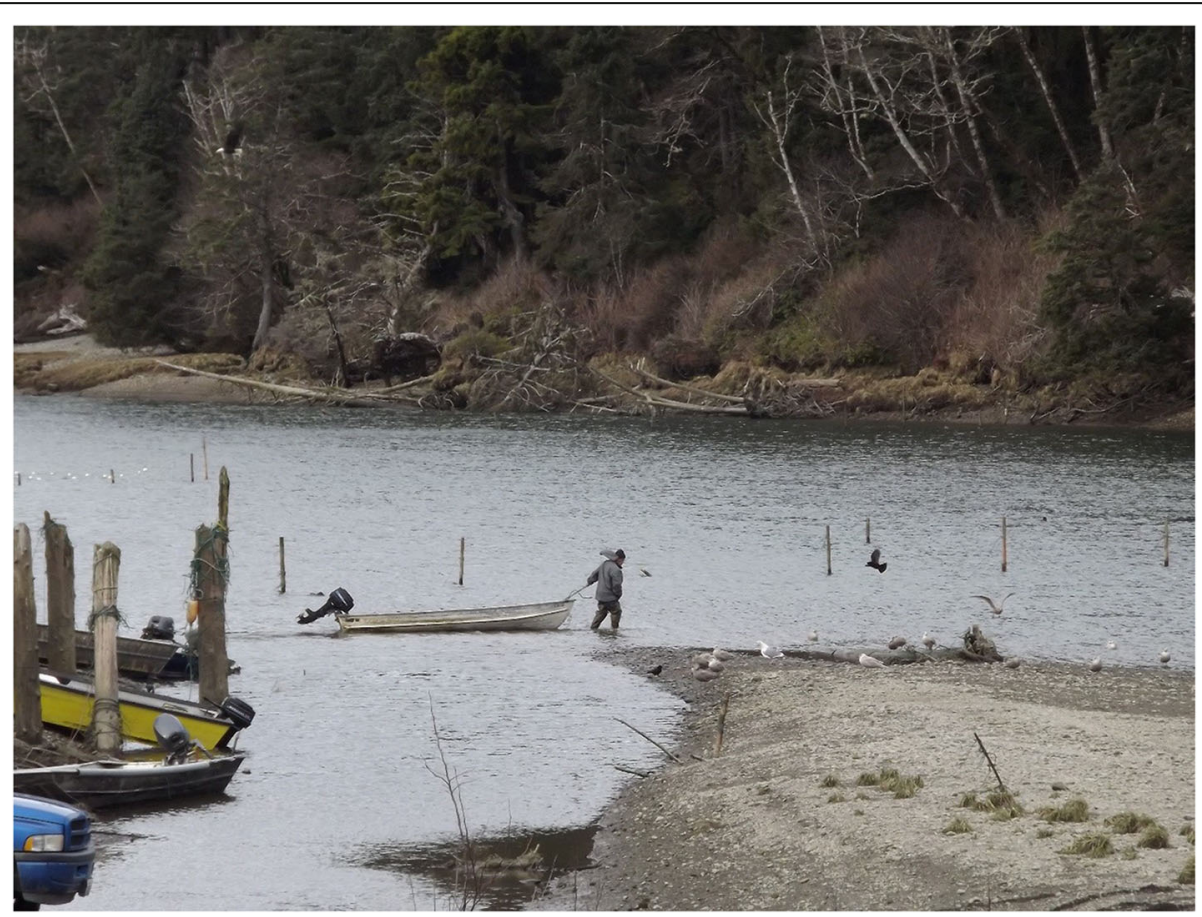

Fig. 1 Map showing tribal lands in the western USA and the locations of the five tribes on which this study was based 
cultural expertise, and were identified by tribal resource managers who assisted in the selection process for this project. Snowball technique was applied, as was purposeful sampling and identification. Data was analyzed utilizing TEK information, relating to the topics addressed previously as they related and were utilized in traditional Native American culture practices and behaviors. Stories, anecdotes, and traditional information systems were all scanned and analyzed for TEK information. Sensitive information and/or intellectual property was not disclosed to the public and is not included in this information because of sovereignty and intellectual property rights of the respective tribes. Analyses were based on documented information systems that have been passed down, as well as traditional information systems that are based in TK and are applied, utilized TEK methodologies. These knowledge systems operate on well-defined and precise practices, and are adjusted in a variety of ways to account for changes in environmental factors. These adjustments were noted and comparisons were made to self-reported previous behaviors to decipher the levels of change and seasonality that have been impacted. Terminology which is rooted in TK and/ or TEK was noted and adjusted for as it differs from western science terminology just as a foreign language would. Some TEK terms are rooted in Native base languages, and cannot be fully translated.

Interviews lasted for $1 \mathrm{~h}$, on average. Interviews were informal and semi-structured, allowing participants to lead discussions. Interviews were audio recorded, brought to Oregon State University, evaluated, and transcribed for further review. All interviews were subject to intellectual property rights restrictions of the tribe (Williams and Hardison 2013). We provide analysis and examples of data here, with permission; but full transcripts are owned by the respective tribes.

\section{Results}

Our analysis of the interviews suggested four significant conclusions, which are each outlined in the next four subsections. We reflect on (1) tribal perspectives on time and seasonality, (2) temporal adaptations, (3) construction of time from the perspective of climate science, and (4) perceived association of climatic change in relation to other changes.

\section{The importance of time, seasonality, and relationship}

For these tribes, the most culturally significant aspect of climate change is how it affects the definition of time, and particularly seasons. Our study found that the tribal understandings of time are defined by cues and patterns observed in the natural world. As such, time is then relied on, operated in, and based on a 3D construction rather than the westernized linear time system. Their concepts of time are important not least because they indicate when certain traditional behaviors should begin, for example, hunting, fishing, and gathering. They are also strikingly relational, so that seasonal patterns are observed as an intricate system of connectivity and integration among plant, animal, insect, and human experience.

These cues for human behavior include weather events, like the first appearance of snow on a certain mountain, botanical indicators like when berries emerge, and animal behaviors like the emergence of a certain species of ant.

"... in the spring, you got carpenter ants, big black carpenter ants, and [eel hunters] didn't go eeling until they saw those carpenter ants, they came out to mate, grow wings and fly off and start new colonies and stuff and that was what they marked when the weather was right to start eeling.... they marked other things the same way, but you can't do that anymore because our weather's changed so much that you can't mark anything like that; there's no way to do it."

(Oscar Hatfield, CTSI Elder)

In the above example, the carpenter ants have no direct biological connection to the spawning times of "eels" (Pacific Lamprey) or water levels, yet the emergence of the ant colonies historically corresponded to eel patterns in the river, and the Siletz relied on this correspondence to know when to go eeling, like a timer going off. This example is also directly (if implicitly) related to climate change caused by rising greenhouse gases, as noted by the comments on changing weather. Winter seasons are shorter and spring seasons are notably occurring earlier in the Pacific Northwest.

Quinault tribal member Doug James gave a similar account relating to Blueback salmon: "The older guys used to tell us that when the salmon berries start coming out, you'd start throwing your net out for blueback, and when we start seeing the salmon berries start coming out, we'd start seeing one or two even if they were games (not full runs, but isolated fish that indicated runs were arriving)." Figure 2 shows a Quinault tribal member fishing.

Disruption of the seasonal cycle, consequently, has profound effects for Native cultures. When a changing climate alters long-established associations between phenological events as in the examples above, the consequences are not merely an inconvenience or a set of information; instead, they challenge the fundamental belief about how elements of the natural world are connected, as well as the timing of when traditional patterns occur and behaviors are performed. Bonds between species such as those between carpenter ants and eels, between salmon berries and blueback, represent a fundamental 


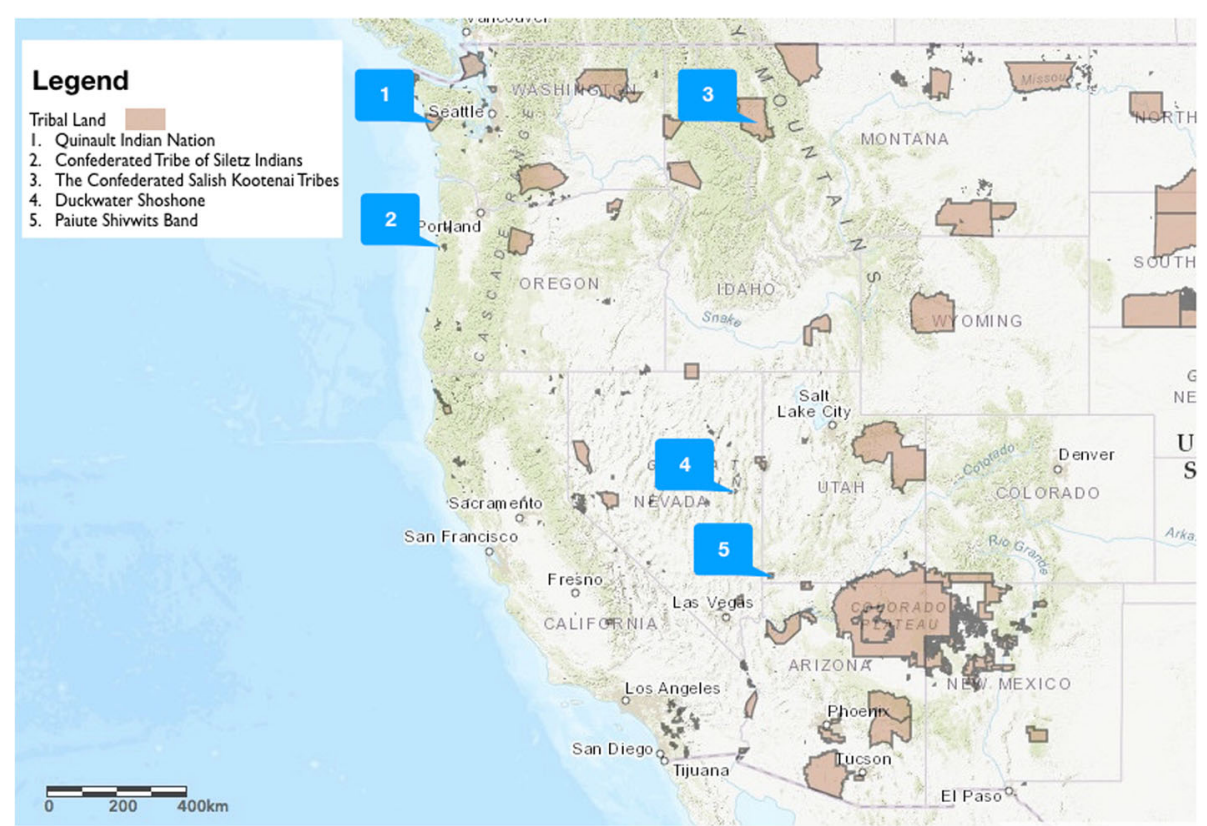

Fig. 2 Quinault tribal member fishes in a traditional family fishing location where TEK is relied upon for fishing harvests

order of the universe; when these bonds dissolve, the sense of order begins to fray and several interviewees expressed confusion, dismay, and concern, as in the last part of Hatfield's remark.

These phenological events are indicators of what is referred to sometimes in Native communities as Indian time-understood here as precision in timing, oriented in relationship to other environmental phenomena and in relationship to appropriate behavior and action. Cycles of events, bound together, not only show these patterns of seasonality, but illustrate the sensitivity with which relationships among people, animals, plants, and landscape may be observed and interpreted. While phenology and relationality do appear in Western science, particularly in noting climatic changes (e.g., Menzel et al. 2006), the primacy of relationality as a mechanism of knowing and identifying change, and the inclusion of right human behavior within these relations, we see as distinct from most western science frameworks and understand it as an epistemological difference between these ways of knowing.

\section{Some aspects of traditional culture are adapting to timing shifts}

Some traditional cultural elements or events are being altered in ways that many members see as temporary, and short term, compared with the extensive period that Natives have been in their aboriginal landscapes. Examples that arose in our interviews included those linked with seasonal indicators.
A seasonally important time period (generally winter, but it varies with each tribe's customs and beliefs) are those days, weeks, or months when some tribes deem it traditionally appropriate to "talk story," and thereby to transmit and sustain traditional information. The term "story" is a misnomer, as this period of time is quite literally an Indigenous informational data system within respective tribes. For Confederated Salish Kootenai Tribes, traditional "talk story" time began when a snowfall of several inches visibly covered the nearby mountains. Owing to the shifts in autumn snowfall timing, the beginning of this time has changed. Due to lessened snowfall amounts, adaptations have taken place. Now less snow is required to indicate when "talk story" time begins. Time, measured as periodic, and timing, understood as onset or co-occurrence of related events, are both important in traditional practice. Adaptive responses, in this case, is offsetting the change in snow with a change in defining appropriate behavior, or timing, thus minimize the effects of climate change on some practices.

\section{Climate science and assumptions about time and seasonality}

In our study region, the Pacific Northwest, changes in climate have been observed over roughly the last century. The most recent and comprehensive study calculated an annual mean warming of $0.6-0.8{ }^{\circ} \mathrm{C}\left(1.3{ }^{\circ} \mathrm{F}\right)$ in the Pacific Northwest from 1901 to 2012 and demonstrated that the warming is anthropogenic (Abatzoglou et al. 2014). Several other metrics of climate changed 
too, including a large rise in the coldest night of the year, lengthened freeze-free season, and increased growing-season evapotranspiration. Abatzoglou et al. (2014) found no change in annual total precipitation since 1901, though there were shorter term trends in precipitation during certain seasons. Numerous studies have documented other aspects of climate change in the western USA, including timing in the arrival of spring (Cayan et al. 2001), spring runoff arriving earlier (e.g., Stewart et al. 2005; Fritze et al. 2011), reduced mountain snowpack (Mote et al. 2018), changed timing of spring fish migration (Robinson and Bayer 2005), and increased wildfire activity (Abatzoglou and Williams 2016), to name a few.

In order to meet stringent statistical requirements, such studies typically describe change over periods comparable to the change in radiative forcing (decades) and dismiss as "noise" shorter term variations, especially if they are not statistically attributable to identifiable causes (as is the case for precipitation). Indeed, shorter term trends can be so dominated by statistical 'noise' that they are in the opposite direction as the forced response (e.g., spring cooled 1980-2012, Abatzoglou et al. 2014). By contrast, Indigenous and other experiential views of climate may be more sensitive to more subtle changes because they are focused on the interactions among constituents in an environment in nuanced ways. This relational quality is a benchmark of significance in our interviews.

In mainstream climate science, seasonality can be defined in several ways. Climate data are often averaged into 3-month seasons (December-February is winter, etc.), but seasons can also be defined in other ways, like growing season or rainy season. Some studies also focus on the timing of key events and how they are shifting: first fall freeze is coming later (Kunkel et al. 2013), lilacs are blooming earlier in the spring (Cayan et al. 2001), peak spring flow is shifting earlier in snowmelt-driven basins (Stewart et al. 2005), and lakes are freezing later in fall and melting earlier in spring (Benson et al. 2012), to name a few. In the Northwest, the freeze-free season has lengthened by about 9 days (Abatzoglou et al. 2014).

Such descriptions of seasonal change, focusing on timing, are relatively rare in academic papers describing climate; most papers focus on the changes in quantitative attributes within a 3-month season (i.e., spring is always March through May, MAM). Even rarer in the climate science literature is a holistic description of change; for example, Cayan et al. (2001) describe both interannual variability and long-term change in spring (MAM) temperature, date of lilac bloom, and date of spring snowmelt runoff. By contrast, the Native TEK view of seasons is entirely about timing and connections; seasonality is emergent and describes how the whole system changes, and how interactions among things are moving in relationship to one another.

\section{Grounding the view: climate change in perspective}

Perhaps the most striking difference between our interviews and climate science is that our interviewees described the changes in environment, culture, ceremony, and socio-politics together, as a body of observable changes over a centuries-long period of time. Regardless of cause, all interviewees were hesitant and anxious about the manner, rate, and sustainability of resource use. This anxiety, which extends to resources not yet in decline, stems from uncertainties that cannot be explained with the traditional stories, songs, or cycles that have been witnessed and conveyed for generations. TEK, then, has been rendered inconsistently reliable by climate-driven uncertainty. This longstanding traditional way of discussing change as a whole was contrasted with the generally more compartmentalized climate science literature, which only rarely produces a holistic or integrated view of climate change within larger socio-political or human-ecological contexts (e.g., Pachauri et al. 2014).

The scope of observable change demonstrated by interviewees is profound, even to the point of altering foundational ceremonies. For example, in the traditional marriage ceremony of the Siletz, a woman accepted a man's marriage proposal, in response he gave a dowry to her family, she then would move into their new home and make ceremonial acorn soup; the soup completed the marriage ceremony, and the couple was then considered married. For complex reasons including the Tribe's relocation in the 1850 s but also the dwindling population of oak trees in western Oregon, the acorn soup part of this ritual is no longer practiced. Invasive species like Scotch broom and Himalayan blackberry prevent survival of oak seedlings, which require moist soil and ground cover of leaf litter for propagation and survival.

Additionally, the Quinault Indian Nation described the traditional practice that Elders had for collecting eels (Pacific Lamprey) during the spring. Because the eel population has declined, this collection practice has largely died out, and even the Elders who prepare and consume eels rely primarily on the fish hatchery, which collects a few every spring, mainly for the Elders who request them. Justine James (QIN) states: "A lot of the eels in this area, they started going out in about the $60 \mathrm{~s}$, some of the Elders still follow that old life-way of eating, preparing eels, and it's kind of a dietary change and the logging practices have kind of altered the environment and so you don't get the eels as much." Close et al. (2002) suggest that the decline may have been exacerbated by a Euro-American notion that the Pacific lamprey is a pest and managed it as such. 
Nearly every participant described changes they had observed and expressed anxiety about these changes, but also expressed apprehension about future changes. These perspectives included changes resulting from a host of factors connected to the cataclysmic replacement of an Indigenous management system of the socio-political and natural environment in North America, with a Western management system. The latter system has brought assimilation pressures, economic upheaval, increases in invasive species, ecosystem changes, and climate change together. In other words, by not compartmentalizing climate change from other human-environmental changes, connections among human action and resulting risk to animal and plant species are more visible in a TEK epistemological construction of climate change.

We argue this difference in assessment, in part, has to do with the organization of knowledge, knowledge construction, and understandings of time and temporality. Understanding inter-relational change puts the events described above in a temporal field that understands changes as dense, intimate to place, interrelated, and across systems, including and especially in changes to socio-political systems and the impacts of colonialism writ large (Killsback 2013). Whereas the primary emphasis in TEK is holistic, the primary emphasis in climate science literature is in thoroughly understanding each component (e.g., physics of sea ice), with much less attention given to seeking connections (as in Cayan et al. 2001) or understanding strong interrelationships. Climate science has developed complex earth system models representing the physical and biophysical components and their interactions (e.g., Flato et al. 2013) and also integrated assessment models representing the interactions between humans (chiefly as their activities affect the radiative energy balance of the planet) and the climate system (e.g., Clarke et al. 2014). Such tools are intended to emphasize interactions and connections among components, and though the two epistemological constructions might share many overarching goals, they also have clearly different approaches and aims.

\section{Discussion}

\section{Epistemological differences and suggestions moving} forward

Differences between these perspectives on time are multifaceted and range from pragmatic to deeply philosophical. To begin with, there are species management implications to our work. We find that with disruptions in seasonality and availability, tribal communities need flexibility in management systems in order to access traditionally harvested resources. However, the "calendar-driven" agency rules about harvest present a challenge. Namely, the defined "season" for harvesting salmon, deer, and shellfish is in some cases in conflict with the actual season of availability. As one elder said, "Our weather is changing, our seasons are not definite like they used to be and you used to be able to count on the rains coming, in October, that brought you the fish up the river so we could catch fish and now sometimes you don't have any rain clear into December." (Oscar Hatfield, CTSI Elder). Specifically, Oregon salmon harvesting season is established by the state department of Fish and Wildlife. The season generally begins in the middle of September and goes through the end of November, depending on location (ODFW 2014). Our research suggests that, not only should the "timing" of the "salmon season" be revisited under conditions of climate change, but that tribal communities need flexibility in determining when is the most appropriate time to harvest species because seasons of "onset" are in flux. In other words, management should be more on Indian time.

Second, we recognize that Traditional Ecological Knowledge may be particularly sensitive to changes in co-occurring temporality-shifts because of a focus on relationality, as per our examples above. Traditional Knowledges maintain vast cultural information, in addition to TEK maintaining profound knowledge of landscapes and seascapes over time, and may observe temporal relationships and changes that exceed the capacity of Western science methods to measure. Thus, we suggest that there is potential for collaboration among Indigenous TEK holders and climate scientists. However, there must be appropriate sharing of epistemological underpinnings if this relationship is to be fruitful and maintain respect for all knowledge holders.

Last, we want to acknowledge that Indigenous communities are disproportionately impacted by climate change because of the strong reliance on subsistence resources, and because of the lack of flexibility to adapt to changes because of colonial legacies and other social and environmental change including inequitable access to economic capital and resources, invasive species disruptions, and other changes over the last 150 years, discussed above (Marino 2015; Whyte 2016a; Wildcat 2009). Adaptation to climate change in tribal communities, therefore, is not absolutely distinct from other cataclysmic changes in tribal communities within Traditional Knowledge sets. Following, adaptation to climate change cannot be done realistically without addressing rights to sovereignty, land rights, treaty rights, and other environmental injustices and changes.

\section{Conclusions}

Ultimately, we see Indigenous concepts of time in this study as 3D, integrating observations and knowledge about the environment, knowledge of cultural tradition, environmental awareness, application of longstanding 
Traditional Knowledges, reliance on and understanding of environmental cues, and finally, finding the right moment or "time" to act based on environmental indicators. These frameworks for time are built into systems of knowing that are complex and sensitive to change. As environmental systems change and there is a decline of certain resources, it poses a challenge to the very basis of how Native identity is formed and maintained. The identity and the robustness of socio-ecological relationships that Natives have been basing themselves on and with for many generations is steeped in this Traditional Knowledge and relationship of reciprocity with the environment. For scientists who wish to work with Native peoples, and for the purposes of advancing climate knowledge in general, special attention should be paid to the relational and seasonal frameworks with which Traditional Ecological Knowledge and Indigenous scientists interpret the natural world. Awareness of differences in temporal constructions of knowledge is essential for cross-epistemological sharing, for maintaining respect across knowledge holders, and for seeing climate change as it really is.

\section{Endnotes}

${ }^{1}$ We define climate science as all branches of science that deal with the description of climate variability and change itself, and of its impacts on the natural world, on infrastructure, and on human well-being, economics, etc. And we distinguish TEK from "mainstream" science-the latter deriving value from peer review, the former deriving value from social acceptance within the community.

\section{Abbreviations \\ CTSI: Confederated Tribes of Siletz Indians; GBLCC: Great Basin Landscape Conservation Cooperative; IK: Indigenous Knowledge; NW: Northwest: QIN: Quinault Indian Nation; TEK: Traditional Ecological Knowledge; TK: Traditional Knowledge}

\section{Acknowledgements \\ The authors wish to thank the Confederated Salish Kootenai Tribes, the Confederated Tribes of Siletz Indians, the Paiute Shivwits Band, the Duckwater Shoshone, and the Quinault Indian Nation for their gracious hosting and sharing of selected information about traditional culture. The project described in this publication was supported by the Department of the Interior Northwest Climate Science Center (NW CSC) through a Cooperative Agreement G13AC00264, by NOAA (grant NA100AR4310218), and the Great Basin Landscape Conservation Cooperative.}

\section{Ethical approval and consent to participate}

The participants were chosen based on their cultural expertise, and were identified by tribal resource manager who assisted in the selection process for this project.

Recruitment Tribal Cultural Resource Departments were contacted via phone calls and/or emails to initially identify interest in the project and to provide guidance on key tribal individuals as possible participants. Purposeful sampling is then commenced by identifying key respondents who held critical information. Individuals identified as having critical information to this research study were then contacted through the respective tribal cultural resources department, or through phone calls. Interviews were arranged through the respective tribes' cultural resources department when possible.
The researcher directly contacted individuals not arranged through the tribal department representatives to schedule interviews when it was appropriate. Upon agreement of the individuals, a meeting date and time was established for the interview.

Oral Consent Process: The oral consent process occurred as outlined in the Oregon State University Institutional Review Board guidelines

(http://oregonstate.edu/research/irb/exempt\%2D-review), and the Northwest Portland Area Indian Health Research Board

(http://www.npaihb.org/health-research/). Standard informed consent information was provided.

Consent obtained in person: Participants were handed the printed verbal consent document after they had been contacted and agreed to meet, prior to being interviewed. The project was explained verbally following the outline of the printed verbal consent document. Participants were notified that copies of the taped interviews would be sent to their tribe, and other redacted copies would be stored at USGS, and/or the Oregon State University Library Archives. The participants would be interviewed at the location they suggested for the interview, or at the respective tribal center if no specific suggestions were made. The estimated time commitment for a participant's involvement was approximately an hour, though actual time depended on participant's responses. Interviews were informal and semistructured, allowing for participants to lead discussions where they felt information was relative to the question prompts.

\section{Funding}

This study was funded by the Department of the Interior Northwest Climate Science Center (NW CSC) through a Cooperative Agreement G13AC00264, by NOAA (grant NA100AR4310218), Great Basin Landscape Conservation Cooperative grant.

\section{Availability of data and materials}

Transcriptions of research interviews are housed at Oregon State University, and with the tribal governments.

\section{Authors' contributions}

Each author wrote specific contributions, and all edited all sections prior to the agreement of the final manuscript approval.

\section{Authors' information}

Chisholm Hatfield is an enrolled member of the Confederated Tribes of Siletz Indians and is also Cherokee. Her expertise is in that area Traditional Ecological Knowledge of Indigenous peoples. She is an active sitting board member for the Oregon State University Klatowa Eena Native American Longhouse and regularly mentors Native students. She has been a Korea Foundation Field Research Fellow and HJ Andrews Academic Writers in Residence Visiting Scholar. She assisted with facilitation, coordination, and advisement of the Northwest Climate Science Center Climate Boot Camp as well as being a featured speaker. She has had her Traditional Ecological Knowledge writings featured in special blogs in Union of Concerned Scientists, Whitefish Review Literary Journal, and Apogee Journal. She has been a speaker at National Congress of American Indians conference, Affiliated Tribes of Northwest Indians conferences, a TEDxSalem speaker, a frequent keynote speaker, and is an active international speaker giving talks about TEK and Indigenous culture

Marino is an Assistant Professor of Anthropology and Sustainability at Oregon State University - Cascades. Elizabeth is an author on the forthcoming National Climate Assessment, has worked with the Humboldt Forum in Berlin on representations of climate change and disasters, and has worked with the Emmet Environmental Law and Policy Clinic at Harvard Law on issues of environmental refugees and displaced peoples. She has also worked with the United Nations University Institute for Environment and Human Security (UNU-EHS) on migration, climate change and humanitarian crisis issues.

Pows Whyte is an enrolled member of the Citizen Potawatomi Nation in Shawnee, Oklahoma. Kyle holds the Timnick Chair in the Humanities in the Department of Philosophy at Michigan State University, is an Associate Professor of Philosophy and Community Sustainability, a faculty member of the Environmental Philosophy \& Ethics graduate concentration, and a faculty affiliate of the American Indian \& Indigenous Studies and Environmental Science \& Policy programs. 
Dello is the Associate Director of the Oregon Climate Change Research Institute and the Deputy Director of the Oregon Climate Service, which is the state climate office for Oregon. Kathie is a skilled climate communicator. She is featured often in the press and gives multiple talks around the region and country. Kathie maintains an active social media presence on her twitter account, @kathiedello.

Mote is the director of the Oregon Climate Change Research Institute (OCCRI) and Associate Dean and professor in the College of Earth, Ocean, and Atmospheric Sciences. He is the co-leader of the NOAA-funded Climate Impacts Research Consortium (CIRC) for the Northwest. He has served as a lead author for the Fourth and Fifth Assessment Reports of the Intergovernmental Panel on Climate Change (IPCC), on three US National Climate Assessments, and seven reports of the National Academy of Sciences. He is President-Elect of the Global Environmental Change Section of the American Geophysical Union.

\section{Consent for publication}

The participants in this study gave their consent to publish this research.

\section{Competing interests}

The authors declare that they have no competing interests.

\section{Publisher's Note}

Springer Nature remains neutral with regard to jurisdictional claims in published maps and institutional affiliations.

\section{Author details}

'Oregon Climate Change Research Institute, Oregon State University, 104 CEOAS Admin Building, Corvallis, OR 97331, USA. ${ }^{2}$ Department of Social Sciences, Oregon State University Cascades Campus, 2600 NW College Way, Bend, OR 97701, USA. ${ }^{3}$ Department of Philosophy, Michigan State University, 503 S. Kedzie Hall, East Lansing, MI 48824-1032, USA. ${ }^{4}$ Department of Community Sustainability, Michigan State University, 503 S. Kedzie Hall, East Lansing, MI 48824-1032, USA

Received: 25 January 2018 Accepted: 13 June 2018

Published online: 09 July 2018

\section{References}

Abatzoglou JT, Rupp DE, Mote PW (2014) Seasonal climate variability and change in the Pacific Northwest of the United States. J Clim 27(5):2125-2142. https:/ doi.org/10.1175/JCLI-D-13-00218

Abatzoglou JT, Williams AP (2016) Impact of anthropogenic climate change on wildfire across western US forests. Proc Natl Acad Sci 113(42):11770-11775

Alexander C, Bynum N, Johnson E, King U, Mustonen T, Neofotis P. Oettlé N et al (2011) Linking indigenous and scientific knowledge of climate change. BioScience 61(6):477-484. https://doi.org/10.1525/bio.2011.61.6.10

Barnhardt R, Kawagaley AO (2005) Indigenous knowledge systems and Alaska Native ways of knowing. Anthropol Educ Q 36(1):8-23. https://doi.org/10. 1525/aeq.2005.36.1.008

Bates P (2007) Inuit and scientific philosophies about planning, prediction, and uncertainty. Arct Anthropol 44(2):87-100

Bennett TMB, Maynard NG, Cochran P, Gough R, Lynn K, Maldonado J, Voggesser G, Wotkyns S, Cozzetto K (2014) Indigenous peoples, lands, and resources. In: Melillo JM, Richmond TC, Yohe WG (eds) Climate change impacts in the United States: the third national climate assessment. U.S. Global Change Research Program. https://doi.org/10.7930/J09G5JR1

Benson BJ, Magnuson JJ, Jensen OP, Card VM, Hodgkins G, Korhonen J, Livingstone DM, Stewart KM, Weyhenmeyer GA, Granin NG (2012) Extreme events, trends, and variability in Northern Hemisphere lake-ice phenology (1855-2005). Climatic Change 112(2):299-323

Benton-Banai E (2008) Anishinaabe almanac: living through the seasons. Kenjgewin Teg Educational Institute, M'Chigeeng, Ontario

Berkes F, Colding J, Folke C (2000) Rediscovery of traditional ecological knowledge as adaptive management. Ecol Appl 10(5):1251-1262. https://doi. org/10.1890/1051-0761(2000)010[1251:ROTEKA]2.0.CO;2

Cameron ES (2012) Securing indigenous politics: a critique of the vulnerability and adaptation approach to the human dimensions of climate change in the Canadian Arctic. Glob Environ Chang 22:103-114. https://doi.org/10. 1016/j.gloenvcha.2011.11.004
Cayan DR, Kammerdiener S, Dettinger MD, Caprio J, Peterson DH (2001) Changes in the onset of spring in the Western United States. Bull Amer Meteor Soc 82:399415. https://doi.org/10.1175/1520-0477(2001)082<0399:CITOOS>2.3.CO;2

Charnley S, Fischer AP, Jones ET (2007) Integrating traditional and local ecological knowledge into forest biodiversity conservation in the Pacific Northwest. Forest Ecol and Mgt 246:14-28. https://doi.org/10.1016/j.foreco.2007.03.047

Chief K, Daigle JJ, Lynn K, Whyte KP (2014) Indigenous experiences in the US with climate change and environmental stewardship in the Anthropocene. In: Sample VA, Bixler RP (eds) Forest conservation and management in the Anthropocene: conference proceedings. RMRS-P-71. US Department of Agriculture, Forest Service. Rocky Mountain Research Station, Fort Collins https://www.treesearch.fs.fed.us/pubs/46584

Clarke L, Jiang K, Akimoto K, Babiker M, Blanford G, Fisher-Vanden K, Hourcade J-C, Krey V, Kriegler E, Löschel A, McCollum D, Paltsev S, Rose S, Shukla PR, Tavoni M, van der Zwaan BCC, van Vuuren DP (2014) Assessing transformation pathways. In: Edenhofer O, Pichs-Madruga R, Sokona Y, Farahani E, Kadner S, Seyboth K, Adler A, Baum I, Brunner S, Eickemeier P, Kriemann B, Savolainen J, Schlömer S, von Stechow C, Zwickel T, Minx JC (eds). Climate change 2014: mitigation of climate change. Contribution of working group III to the fifth assessment report of the intergovernmental panel on climate change. Cambridge University Press, Cambridge and New York

Climate and Traditional Knowledges Workgroup (2015) The ethics of traditional knowledge exchange in climate change initiatives. Earth. https:/earthzine. org/2015/07/31/the-ethics-of-traditional-knowledge-exchange-in-climatechange-initiatives

Close DA, Fitzpatrick MS, Li HW (2002) The ecological and cultural importance of a species at risk of extinction, Pacific lamprey. Fisheries 27(7):19-25

Cochran P, Huntington OH, Pungowiyi C, Tom S, Chapin FS III, Huntington HP, Maynard NG, Trainor SF (2013) Indigenous frameworks for observing and responding to climate change in Alaska. Clim Chang 120:557-567. https:// doi.org/10.1007/s10584-013-0735-2

Dalton M, Mote PW, Snover AK (eds) (2013) Climate change in the northwest: implications for our landscapes, waters, and communities. Island Press, Washington DC. https://doi.org/10.5822/978-1-61091-512-0

Davidson-Hunt I, Berkes F (2003) Learning as you journey: Anishinaabe perception of social-ecological environments and adaptive learning. Ecol Soc 8(1):5

Drew JA (2005) Use of traditional ecological knowledge in marine conservation. Conserv Biol 19:1286-1293

Field CB and 58 co-authors. (2014) Technical summary. In: Field CB and 15 coeditors (eds). Climate change 2014: impacts, adaptation, and vulnerability. Part A: global and sectoral aspects. Contribution of working group II to the fifth assessment report of the intergovernmental panel on climate change. Cambridge University Press, Cambridge and New York

Flato G, Marotzke J, Abiodun B, Braconnot P, Chou SC, Collins W, Cox P, Driouech F, Emori S, Eyring V, Forest C, Gleckler P, Guilyardi E, Jakob C, Kattsov V, Reason C, Rummukainen M (2013) Evaluation of climate models. In: Stocker TF, Qin D, Plattner G-K, Tignor M, Allen SK, Boschung J, Nauels A, Xia Y, Bex V, Midgley PM (eds) Climate change 2013: the physical science basis. Contribution of working group I to the fifth assessment report of the intergovernmental panel on climate change. Cambridge University Press, Cambridge and New York

Fritze H, Stewart IT, Pebesma E (2011) Shifts in western North American snowmelt runoff regimes for the recent warm decades. J Hydrometeorol 12: 989-1006. https://doi.org/10.1175/2011.JHM1360.1

Gingrich A, Ochs E, Swedlund A (2002) Repertoires of timekeeping in anthropology. Curr Anthropol 43:S3-S4

Haalboom B, Natcher DC (2012) The power and peril of "vulnerability": approaching community labels with caution in climate change research. Arctic 65:319-397. https://doi.org/10.14430/arctic4219

Harrington J (2006) Climate change, human rights, and the right to be cold. Fordham Envtl L Rev 18:513-535

Hodges M (2008) Rethinking time's arrow: Bergson, Deleuze and the anthropology of time. Anthropological Theory 8(4):399-429

Hong SK, Won YT, Lee GA, Hand ES, Cho MR, Park HY, Kim JE, Chisholm Hatfield S (In Press) Interdisciplinary Convergence Research Design on Island Biocultural Diversity - Case Study in Wando-gun (County) Island Region, South Korea. Journal of Marine and Island Cultures Institution for Marine and Island Cultures, Republic of Korea

Huntington HP (2000) Using traditional ecological knowledge in science: methods and applications. Ecol Appl 10: 1270-1274. https://doi.org/10.1890/ 1051 0761(2000)010[1270:UTEKIS]2.0.CO;2. 
Huntington HP, Fox S (2005) The changing Arctic: indigenous perspectives. Arctic climate impact assessment, 81-98. Cambridge University Press, Cambridge

Killsback L (2013) Indigenous perceptions of time: decolonizing theory, world history, and the fates of human societies. American Indian Culture and Research Journal 37:85-114. https://doi.org/10.17953/aicr.37.4.86k2lh8101521j66

Kunkel KE, Stevens LE, Stevens SE, Sun L, Janssen E, Wuebbles D, Redmond KT, Dobson JG (2013) Regional climate trends and scenarios for the U.S. National Climate Assessment. Climate of the northwest U.S. NOAA Technical Report NESDIS 6:142-146

LaDuke W (2017) All our relations: native struggles for land and life. Haymarket Books, Chicago

Lynn K, Daigle J, Hoffman J, Lake F, Michelle N, Ranco D, Viles C, Voggesser G, Williams P (2013) The impacts of climate change on tribal traditional foods. Clim Chang 120:545-556. https://doi.org/10.1007/s10584-013-0736-1

Maldonado J (2012) Climate change and displacement: human rights and local knowledge as guiding principles for new policy initiatives. In: Hamza M, Corendea C (eds) Climate change and fragile states: rethinking adaptation. https://doi.org/10.13140/2.1.2800.7046

Maldonado J, Lazrus H, Bennett SK, Chief K, Dhillon CM, Gough B, Kruger L, Morisette J, Petrovic S, Whyte KP (2017) The Story of Rising Voices. In Responses to Disasters and Climate Change. 15:(25). ROUTLEDGE in association with GSE Research. https://risingvoices.ucar.edu/sites/default/files/ 2017_Rising_Voices5_Report_final.pdf

Maldonado JK, Shearer C, Bronen R, Petersen K, Lazrus H (2013) The impact of climate change on tribal communities in the US: displacement, relocation, and human rights. Clim Chang 120(3):601-614. https://doi.org/10.1007/ s10584-013-0746-z

Marino $E$ (2012) The long history of environmental migration: assessing vulnerability construction and obstacles to successful relocation in Shishmaref, Alaska. Glob Environ Chang 22(2):374-381. https://doi.org/10. 1016/j.gloenvcha.2011.09.016

Marino E (2015) Fierce climate, sacred ground: an ethnography of climate change in Shishmaref, Alaska. University of Alaska Press, Fairbanks https:// www.alaska.edu/uapress/browse/detail/index.xml?id=528

Marino E, Lazrus H (2016) "We are always getting ready": how diverse notions of time and flexibility build adaptive capacity in Alaska and Tuvalu. In: Button G, Schuller M (eds) Contextualizing Disaster. Berghahn, New York

McNeeley SM, Shulski MD (2011) Anatomy of a closing window: vulnerability to changing seasonality in interior Alaska. Glob Environ Chang 21(2):464-473. https://doi.org/10.1016/j.gloenvcha.2011.02.003

Menzel A, Sparks TH, Estrella N, Koch E, Aasa A, Ahas R, Alm-Kübler K, Bissolli P, Braslavská OG, Briede A, Chmielewski FM (2006) European phenological response to climate change matches the warming pattern. Glob Chang Biol 12(10):1969-1976

Mote PW, Li S, Lettenmaier D, Xiao M, Engel R (2018) Dramatic declines in snowpack in the western US. Nature npj Climate and Atmos Sci. https://doi. org/10.1038/s41612-018-0012-1

ODFW (2014) Coastal fall salmon seasons http://www.dfw.state.or.us/resources/ fishing/coastal_salmon_seasons.asp. Accessed 9 Dec 2014.

Pachauri RK et al (2014) Climate change 2014: synthesis report. Intergovernmental panel on climate change, fifth assessment report. Cambridge University Press, Cambridge and New York

Robinson DA, Frei A (2000) Seasonal variability of northern hemisphere snow extent using visible satellite data. J Prof Geog 52(2):307-314. https://doi.org/ 10.1111/0033-0124.00226

Robinson TC, Bayer JM (2005) Upstream migration of pacific lampreys in the John Day River, Oregon: behavior, timing, and habitat use. J Northwest Science 79(2):106-119. https://doi.org/10.1080/02755947.2014.986344.

Salick J, Byg A (2007) Indigenous peoples and climate change. Tyndall Centre for Climate Change Research. University of Oxford Press, Oxford

Stewart I, Cayan D, Dettinger M (2005) Changes toward earlier streamflow timing across western North America. J Clim 18:1136-1155. https://doi.org/10.1175/ JCLI3321.1

Stewart-Harawira M (2005) The new imperial order: indigenous responses to globalization. Zed Books, London

Stocker TF et al (eds) (2013) Climate change 2013: the physical science basis. Contribution of working group I to the fifth assessment report of the intergovernmental panel on climate change. Cambridge University Press, Cambridge and New York
The Mystic Lake Declaration. (2009) Paper presented at the native peoples native homelands climate change workshop II, prior Lake, Minnesota, 18-21 November 2009

Trosper R (2009) Resilience, reciprocity and ecological economics: northwest coast sustainability. Routledge, London and New York

Vinyeta K, Whyte KP, Lynn K (2015) Climate change through an intersectional lens: gendered vulnerability and resilience in indigenous communities in the United States. US Department of Agriculture, pp 1-74. https://doi.org/10. 2737/PNW-GTR-923

Weatherhead E, Gearheard S, Barry AG (2010) Changes in weather persistence: insight from Inuit knowledge. J Glob Env Chg 20:523-528. https://doi.org/10. 1016/j.gloevcha.2010.02.002

Whyte KP (2016a) Is it colonial déjà vu? Indigenous peoples and climate injustice. In: Adamson J, Davis M, Huang H (eds) Humanities for the environment: integrating knowledges, forging new constellations of practice. Earthscan Publishing, New York

Whyte KP (2016b) What do indigenous knowledges do for indigenous peoples? In: Nelson ML, Shilling D (eds) Keepers of the green world: traditiona ecological knowledge and sustainability. Cambridge University Press, Cambridge

Whyte KP (2018) Indigenous science (fiction) for the Anthropocene: ancestral dystopias and fantasies of climate crises. Environment \& Planning E: Nature and Space Online First:1-18. https://doi.org/10.1177/2514848618777621

Whyte KP, Brewer JP, Johnson JT (2016) Weaving indigenous science, protocols and sustainability science. J Sustain Sci 11:25-32

Wildcat DR (2009) Red alert! Saving the planet with indigenous knowledge. Fulcrum Publishing, Golden

Williams T, Hardison P (2013) Culture, law, risk and governance: contexts of traditional knowledge in climate change adaptation. J Clim Chg 120(3):531-544. https://doi.org/10.1007/s10584-013-0850-0

Willox AC (2012) Climate change as the work of mourning. J Ethics and the Environment 17:137-164

Willox AC, Harper SL, Edge VL, Landman K, Houle K, Ford JD (2011) The land enriches the soul: on climatic and environmental change, affect, and emotional health and well-being in Rigolet, Nunatsiavut, Canada. J Emotion, Space and Society 6:14-24. https://doi.org/10.1016/j.emospa.2011.08.005.

Wotkyns SR (2013) Tribes and climate change.

\section{Submit your manuscript to a SpringerOpen ${ }^{\circ}$ journal and benefit from:}

- Convenient online submission

- Rigorous peer review

- Open access: articles freely available online

- High visibility within the field

- Retaining the copyright to your article

Submit your next manuscript at springeropen.com 